\section{What is the effect of location on rental housing prices in Athens?}

\author{
Jorge Chica-Olmo ${ }^{1}$ \\ Rafael Cano-Guervos ${ }^{2}$ \\ María-Despoina Moschovaki ${ }^{3}$ \\ Ivan Tamaris-Turizo ${ }^{4}$ (ID
}

\begin{abstract}
Purpose - The aim of this study is to quantify the effect of location on rental
\end{abstract} housing prices in the city of Athens.

Theoretical framework - The right to adequate housing is a fundamental human right defended by democratic societies. Therefore, it is of interest to examine housing tenures for both owned and rented accommodation.

Design/methodology/approach - Geostatistical methods (regression-kriging) were used to obtain the results, which are represented on an isovalue map of rental housing prices displaying the minor and major effects of location by zone.

Findings - This study highlights the impact of location on rental housing prices by showing how the rent of a standard dwelling in the city of Athens varies depending on its location.

Research Practical \& Social implications - The main social implications of this work is it helps investors determine where to direct investments and it assists public authorities in deciding where to focus urban management policies, in order to control the undesirable effects of an excessive rise in rents caused by tourism.

Originality/value - The main originality of this paper lies in its isovalue map of rental housing prices for standard dwellings, which can also be interpreted as a locational isovalue map.

Keywords - rental housing prices, geostatistics, isovalue map, effects of location, Athens.

1. University of Granada, Department of Quantitative Methods for Economics and Business, Granada, Spain.

2. University of Granada, Department of Quantitative Methods for Economics and Business, Granada, Spain.

3. Economic analyst, NGA Human Resources, Granada, Spain.

4. International School of Administration and Marketing, Sergio Arboleda University, Santa Marta, Colombia.

How to cite:

Chica-Olmo, J., Cano-Guervos, R., Moschovaki, M., Tamaris-Turizo, I. (2021). What is the effect of location on rental housing prices in Athens? Revista Brasileira de Gestão de Negócios, 23(3), p.439-453.
Received on:

08/16/2019

Approved on:

$12 / 02 / 2020$

Responsible Editor:

Prof. Dr. Joelson Sampaio

Evaluation process:

Double Blind Review

Reviewers:

Fabio Humberto Sepúlveda Murillo; Humberto Gallucci Netto

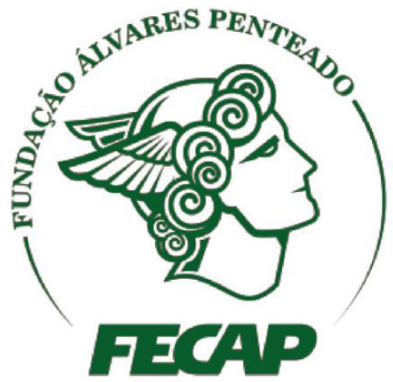

Revista Brasileira de Gestáo de Negócios

https://doi.org/10.7819/rbgn.v23i3.4114 


\section{Introduction}

The right to adequate housing is a fundamental human right defended by democratic societies, and has always formed part of the class struggle (Danieli, Stamatopoulou, \& Dias, 2018; Korpi, 2018). Rex (1968) considered three types of housing tenure: multiple-house owners, homeowners, and renters. These types of tenure gave rise to the concept of housing class developed by Weber, who argued that the class struggle is not only a struggle for the means of production, but also for access to housing (Chen, Wu, Guo, \& Wang, 2018). In addition, "space" can be considered as being where the class struggle takes place given that the upper social classes tend to occupy the best locations, displacing the lower classes towards marginal areas (Goodall, 2013). In fact, according to Tse (2002), as housing prices increase, families tend to move to places with poorer accessibility where prices are generally lower. This spatial segregation gives rise to a concentration of the upper social classes in areas with dwellings of superior quality and location assets, which are therefore more highly priced (Ozanne \& Thibodeau, 1983).

The problem of housing tenures in large cities is currently of great concern to many citizens, particularly young people seeking to become independent. The price of rental properties for residential use is being influenced by the strong demand for tourist rental accommodation, which has given rise to a potential "bubble" in rental prices in some European cities (Blanco-Romero, BlázquezSalom, \& Cànoves, 2018) and what is known as the "turistification" phenomenon.

The rental housing market is an economic activity that consists of renting property acquired through purchase, donation, inheritance, etc. from one individual to another. Investors in this market make long-term financial investments by purchasing properties with the aim of renting them for residential use (buy-to-rent). There are generally two types of rental agreements for dwellings targeted at residential use depending on the period of time stipulated in the agreement: short-term or long-term agreements. Given that investment in housing is typically long term, homeowners, whether they are large or small investors, generally prefer long-term rentals (Wulff \& Maher, 1998). As highlighted by several authors, long-term rentals have traditionally been the object of research given the interest of policymakers and politicians. However, as indicated above, there is currently a boom in another type of apartment rental: tourism rentals, which are in increasing supply due to the potential profits to be gained (Nasreen \& Ruming, 2018).

From the perspective of rental housing management, there are three types of managers: public companies, private companies, and private owners. As Lee (2007) indicated, private owners are generally more common in Western capitalist societies, leading to an asymmetric pattern in public and private housing investment.

Nonetheless, regardless of the type of management or agreement (short or long term), rental housing is one of the main factors that determines housing prices (Gallin, 2008). In fact, one of the most commonly used methods for valuing housing is capitalization, which determines the price of a dwelling based on its rental price (Pagourtzi, Assimakopoulos, Hatzichristos, \& French, 2003). However, this may be subject to an endogenous effect, since rental price is also determined by the price of a dwelling. In some countries, for example, it is a common practice among banks and real estate agents to set a rental price equivalent to a percentage of the selling price. In other words, rent is the dividend in the real estate stock market (Leamer, 2002). Furthermore, the price-to-rent ratio is an indicator of the real estate market, which could have the potential for predicting house prices and determining the factors that explain price evolution over time (Gallin, 2008; Taipalus, 2006).

It may also be of interest to analyze the variation in rental prices in space by taking into account the location of rental dwellings. For this purpose, it is convenient to perform a spatial analysis of rental housing prices using different tools such as geographic information systems (GIS), spatial econometrics, and geostatistics. These tools can assist in determining the effect of location on rental housing prices, which could help investors and public bodies to improve their decision-making processes.

Given the geographical scope of this study, it is important to highlight that, until the 2008 crisis, the building industry was among the most influential sectors in the Greek economy. It was boosted by state development, the government's fiscal and social policies, and the propensity of Greek citizens to own real estate (Papadimitriou, Nikiforos, \& Zezza, 2013). Although housing prices in Greece have fallen by $38.5 \%$ since the crisis (Ramos, 2015), the cost of rental accommodation now represents $40 \%$ of disposable income, while the $\mathrm{EU}$ average is 28\% (Eurostat, 2018). 
As indicated above, rental housing is a subject of social interest. Although this topic has been widely examined using a temporal approach, we believe that the scarcity of studies that use a spatial approach justifies this research. The main objective of this study is to determine the impact of a property's location on its rental price. To this end, we studied a sample of rental housing prices in the city of Athens in the second quarter of 2014.

In what follows, we first present a review of the literature on the importance of location to rental housing prices and describe the methods used. We then discuss the data and results and, finally, draw some conclusions.

\section{Literature Review}

As indicated above, housing can be considered as an investment product whose profitability can be measured by its ability to generate a higher or lower income. Consequently, rental housing prices and their explanatory factors are topics of interest. Hedonic modeling can be used to quantify the implicit prices of factors that determine the overall price of a good (Lancaster, 1966; Rosen, 1974). Hedonic models have been used in a large number of studies primarily to explain housing prices. However, the hedonic housing regression model has received some criticism (Chau \& Chin, 2003), mostly due to the limitations of the classical estimation method used: ordinary least squares (OLS). The use of alternative methods has made it possible to overcome some of the limitations of OLS, such as the weaker explanatory and predictive capacity of OLS in the presence of spatial dependence (Anselin, 1988). Different solutions have been proposed to improve this explanatory and predictive capacity using a spatial model approach.

Within this type of modeling, spatial econometrics have provided the most widely used solutions through the specification of spatial autoregressive (SAR) models, spatial error models (SEM), and geographically weighted regression (GWR) models (see Dubin, Pace, \& Thibodeau, 1999; Krause \& Bitter, 2012; Osland, 2010; Wen, Jin, \& Zhang, 2017). Geostatistical methods have also been successfully used (see Bourassa, Cantoni, \& Hoesli, 2007; Cellmer, 2014; Chica-Olmo, 1995; Dubin, 1992). These methods have the advantage of providing isovalue maps for the analyzed variable. As regards the modeling of rental housing prices, a few studies have used the classical methods (Hoch \& Waddell, 1993; Nishi, Asami, \& Shimizu, 2019; Wheaton, 1977), quantile regression models (Cui, Gu, Shen,
\& Feng, 2018), spatial econometric models (Efthymiou $\&$ Antoniou, 2013), and GWR (Iliopoulou \& Stratakis, 2018). Studies using geostatistical methods are virtually non-existent, hence one of the main novelties of this study. The common denominator in these methodologies is that they consider the spatial component as a key element for the modeling of rental housing.

From a theoretical perspective, the spatial component must be considered when explaining rental housing prices. In the case of monocentric cities, the classic urban land bid rent theory establishes that real estate rents decrease as the distance to the city center increases (Von Thünen, 1966). This theory also applies to polycentric cities (Harris \& Ullman, 1945). These approaches take into account friction costs associated with accessibility, which is measured as the distance from a dwelling to the central business district or the cost incurred or time spent traveling between the two. Some authors argue that there is a relationship between utility and rent maximization, which would ensure that location and rent patterns are identical (Wheaton, 1977). In fact, according to Alonso (1964), "location" is a hedonic good whose value should be explained.

The factors that determine the price of housing have been traditionally classified into structure, accessibility, and neighborhood attributes (Can, 1992; Chica-Olmo, 1995; Dubin, 1998). Of these, the structural characteristics of dwellings are relatively easy to measure and are generally included in publicly-available data. These characteristics include floor area, number of rooms, age, and the general physical or structural characteristics of the dwelling.

Figure 1 shows the structural characteristics considered in this study. However, accessibility and neighborhood attributes are closely related to the location of each dwelling in a specific area. For example, transport, nearby services of different kinds, accessibility to one's workplace and different places of interest, and the quality of the neighborhood and environment are just some of the characteristics that give each residential unit a unique set of attributes depending on the location (Efthymiou $\&$ Antoniou, 2013; Tse, 2002). Location characteristics are not always easy to measure although they form part of the price, and as such the price of a dwelling will be affected by its location (Chica-Olmo, Cano-Guervos, \& Chica-Olmo, 2013). What these characteristics have in common is that they depend on location. As a result, some authors, such as Dubin (1992), have stated that the three most important factors that determine housing prices 


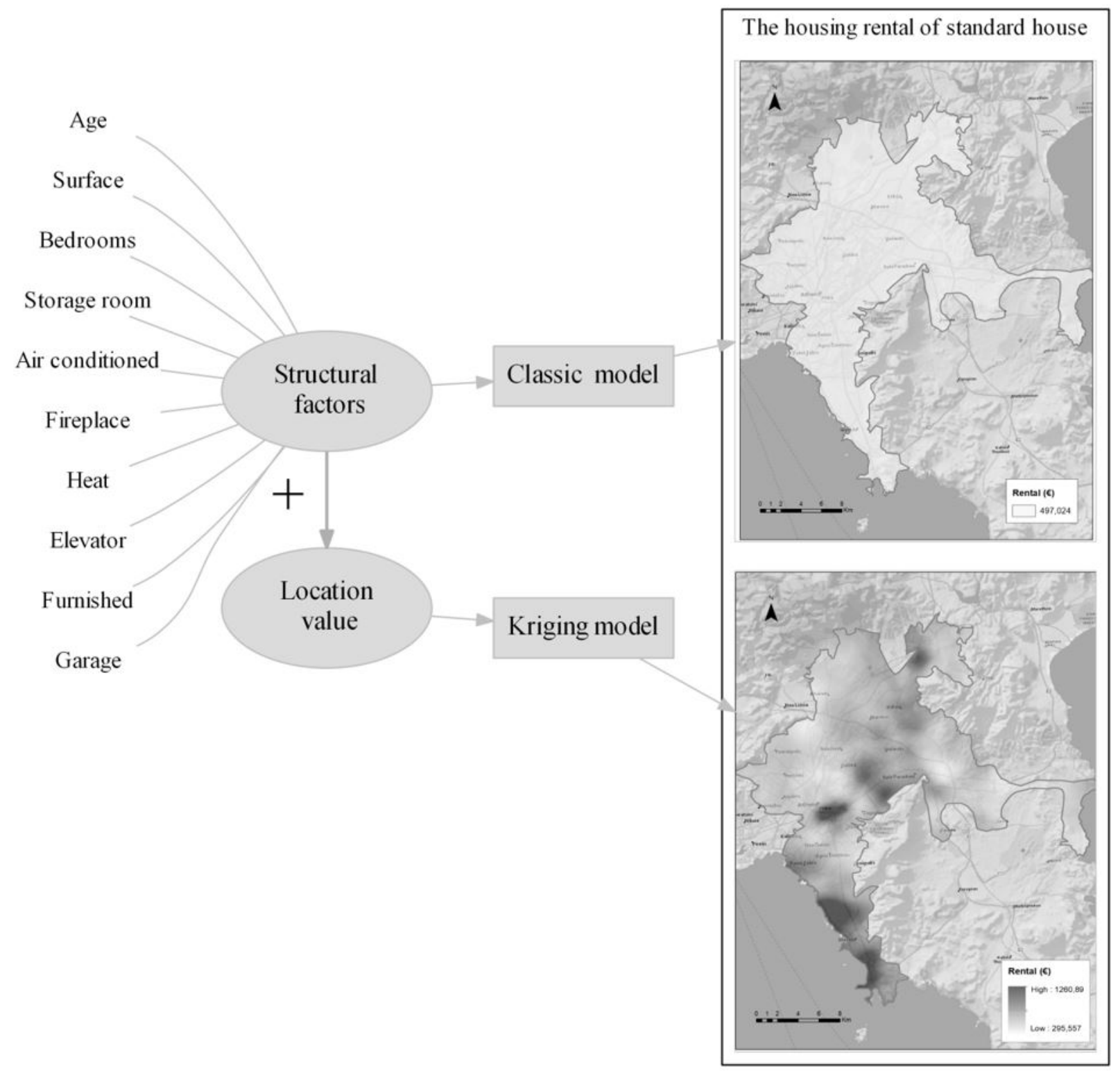

Figure 1. Factors that influence rental housing prices and models

are location, location, and location. It is evident, then, that accessibility and neighborhood characteristics (i.e., location components) should affect rental housing prices, although, as said, they are not always easy to measure.

For example, location attributes related to accessibility, such as proximity to the central business district, workplaces, main transport routes, public schools, and shopping centers, among others (Chen \& Jim, 2010; Chica-Olmo, Cano-Guervos, \& Tamaris-Turizo, 2018; Efthymiou \& Antoniou, 2013; Trojanek \& Gluszak, 2018), require the unit of measurement to be determined (distance, time, or cost). At other times the difficulty lies in determining the area of influence pertaining to the previously mentioned factors or other factors, such as ethnicity, crime rate, and environmental factors, such as noise and air pollution (Beimer \& Maennig, 2017; Fabusuyi, 2018; Le Boennec \& Salladarré, 2017; Moye \& Thomas, 2018; Swoboda, Nega, \& Timm, 2015). Location factors are more difficult to measure than structural characteristics (Basu \& Thibodeau, 1998). In addition, when assessing the effects of location components, it is difficult to determine neighborhood boundaries and what measures to use to determine those boundaries (Diao, Leonard, \& Sing, 2017; Diao, Qin, \& Sing, 2016). As a result, there are areas where boundaries are quite obvious, such as municipal boundaries, school district boundaries, 
and other boundaries based on geographical elements such as highways, roads, rivers, and parks (Fan, Hansz, \& Yang, 2016). However, there are other areas where neighborhood boundaries are not as evident. Despite these difficulties, it is important to incorporate the impact of location when estimating hedonic rental housing prices (Basu \& Thibodeau, 1998) given that location is considered to influence both the selling price and the rental price of a dwelling (Efthymiou \& Antoniou, 2013).

The omission of location variables in the regression model leads to bias in the OLS. Spatial autocorrelation can be observed in the disturbances when location variables are omitted. Nishi et al. (2019) quantified the bias caused by the omission of factors that determine the rental price of dwellings in Tokyo, Japan. However, spatial prediction methods, such as geostatistical methods (kriging), can reduce bias by taking into account autocorrelation in disturbances (Dubin, 1988). Autocorrelation is caused by the first law of geography, according to which "everything is related to everything else, but near things are more related than distant things" (Tobler, 1970, p. 236). In the case of housing, autocorrelation occurs for several reasons. Given that neighborhoods generally develop at the same time, properties have very similar structural characteristics, such as size or design. In turn, dwellings belonging to the same area share the same advantages and disadvantages of location (Basu \& Thibodeau, 1998).

The effect of spatial contagion caused by the transfer of information between neighboring homeowners in a space regarding the predominant prices of the area must also be taken into account. All of these factors influence both housing and rental prices (Hoch \& Waddell, 1993), sometimes positively and sometimes negatively. In short, the effect of location should be considered in a hedonic model.

If rental housing prices are estimated using a traditional hedonic regression model (OLS) that does not consider the effect of location on prices but only the structural characteristics of a standard dwelling, the estimates would be the same for the entire geographical space. In contrast, the kriging model accounts for the effect of location, and hence the rent for a standard dwelling will vary depending on its location (see Figure 1).

The main interest of hedonic models is that the implicit price of each of the characteristics that determine rental housing prices is quantified in the model coefficient. That is, the adjusted regression model estimates the influence of each of the housing characteristics on rental housing prices. This work proposes a method that can be widely applied, since it only requires information that is generally available on many real estate websites (rental housing prices, certain structural characteristics of the dwellings and their locations). The second reason for using this method is that it allows property values, which are sometimes overly subjective, to be estimated in an objective manner, especially with regard to locational factors. The third reason is that the method not only enables the rental price of a particular property to be calculated, but it can also be used for mass valuations of homes, thus making it an effective tool for real estate and construction companies, real estate investment funds, financial and mortgage entities, as well as public administrations for the purposes of taxation or urban management.

\section{Methods and data}

\section{Methods}

Geostatistics is a science that facilitates the analysis of spatial data using spatial quantitative techniques. Geostatistical models are based on the estimation of a variances-covariances matrix of disturbances to subsequently estimate the model parameters (Cressie, 1991).

Kriging is a spatial prediction method used in geostatistics to minimize the quadratic error and obtain weights that depend on the distances between individual dwellings and the dwelling being assessed. The autocorrelation structure is detected by means of a variogram (Matheron, 1970). Kriging generally attributes less weight to dwellings farthest from the one being assessed and more weight to the nearest ones. Therefore, kriging can be considered a weighted average technique that takes into account the presence of spatial autocorrelation (Felus, 2001).

Based on the widely accepted hypothesis in the literature that the value of urban properties is fundamentally conditioned by structural and locational characteristics, a method is proposed for estimating urban rental housing prices taking into account the influence of both types of characteristics. Specifically, the method used is geostastical kriging combined with econometric regression. Because this is a widely-known method, an in-depth explanation is not provided in this paper.

One variant of the kriging method is regressionkriging $(\mathrm{RK})$, which is a combination of econometric and geostatistical methods (Chica-Olmo, 1995; Dubin, 1992; Hengl, Heuvelink, \& Rossiter, 2007). Some recent studies 
have applied this methodology in the field of property valuation, particularly for house price valuations (Bajat, Kilibarda, Pejović, \& Petrović, 2018; Chica-Olmo, CanoGuervos, \& Chica-Rivas, 2019). To estimate the rental prices of houses located at point $s_{0}$, whose price is not known, the following best linear unbiased predictor can be used (Christensen, 1987):

$$
\hat{y}\left(s_{0}\right)=x\left(s_{0}\right)^{\prime} \hat{\beta}+\lambda^{\prime} e\left(s_{i}\right)
$$

where $x\left(s_{0}\right)$ is a vector which represents the values of the independent variables (apartment age, surface area, bathrooms, etc.) in $s_{0} ; \hat{\beta}$ is the vector of parameters estimated by generalized least squares (GLS); $\lambda$ is the vector of kriging weights and $e\left(s_{i}\right)$ is a vector of residuals in the sample points, $s_{i}$. These weights $(\lambda)$ are obtained taking into account the spatial autocorrelation structure given by the variogram function $(y(h))$ (Matheron, 1970). In our study, the residuals represent the effect of the location variables not included in the regression model. The spatial autocorrelation structure of the residuals is determined by the following empirical variogram:

$\hat{\gamma}_{e}(h)=\frac{1}{2 N(h)} \sum_{i=1}^{N(h)}\left[e\left(s_{i}+h\right)-e\left(s_{i}\right)\right]^{2}$

where $\left(s_{i}+h\right)$ and $\left(s_{i}\right)$ are the location of the apartments in the sample and $N(h)$ is the number of $h$ distant locationpairs. To apply the kriging method, it is necessary to adjust the empirical variogram model. The exponential model is one of the most widely used models in the literature (Webster \& Oliver, 2007):

$$
\text { Exponential model: } \gamma(h)=\left\{\begin{array}{cc}
C_{0}+C\left[1-\exp \left(-\frac{h}{a}\right)\right] & |h|>0 \\
0 & |h|=0
\end{array}\right.
$$

where $C_{0}$ is the nugget effect, $a$ is the range, $C$ is the partial sill, and the effective range is equal to $3 a$. The range measures the distance at which the location variables cease to have an influence on rental housing prices.

\section{Data}

Athens is the capital of Greece and currently the country's largest city. It is the main center of Greek economic, cultural, and political life. The metropolitan area of Athens extends over the plains of the Attica peninsula, and is bordered by the Saronic Gulf to the south, Mount Aigaleo to the west, Mount Parnitha to the northwest, Mount Pentelicus to the northeast, and Mount Hymettus to the east. The original city of Athens was in the center of the plain but following the urban expansion in the $20^{\text {th }}$ century the city has merged with surrounding populations, giving rise to the metropolitan area, which includes 54 municipalities.

In order to study apartment rental prices in the city of Athens, a sample of 757 residential apartments distributed throughout the city was collected in the second quarter of 2014. Given that there is no official register of rented housing (Magginas \& Pateli, 2009), the data for this study were obtained from various real estate company websites (www.tospitimou.gr, www.spitogatos.gr, www. spiti24.gr, www.acropolis-realestate.gr).

The dependent variable in the model is rental housing price measured in euros (Rental housing). The explanatory variables are primarily structural characteristics. As a result, we have included the age of the building in years (Age); total built surface area in square meters (Surface); number of bedrooms (Bedrooms); number of additional toilets apart from the main bathroom (WC); whether or not the dwelling has a storage room (Storage room); whether or not it has air conditioning (Air conditioned); whether or not it has views (View); whether or not it has a fireplace (Fireplace); whether or not it has heating (Heat); whether or not it has an elevator (Elevator); whether or not it is furnished (Furnished), and whether or not it has a garage (Garage). The basic descriptive statistics of all the variables are shown in Table 1 .

Figure 2 shows the spatial distribution of the housing in the sample and the rental price per square meter in Athens by quintiles. The results show that the highest prices are concentrated in the Acropolis area, which occupies part of the city center (corresponding to the major tourist area); in Glyfada, which is in the south of the city (coastal area); in the northeast, and in some areas of the north where there are numerous luxury homes. In contrast, the lowest prices are found in the central area north of the Acropolis, close to several universities, as well as in the eastern and western areas furthest from the city center.

\section{Results and Discussion}

In this study, we used a semi-logarithmic hedonic model widely employed in the literature on property values (Nishi et al., 2019). This type of specification facilitates normal model disturbances and interprets the model 
Table 1.

Descriptive statistics of the variables

\begin{tabular}{|c|c|c|c|c|c|}
\hline & Mean & Mode & SD & Min & Max \\
\hline \multicolumn{6}{|l|}{ Dependent variable } \\
\hline Rental housing prices & 817.713 & 800 & 673.819 & 120 & 6,000 \\
\hline \multicolumn{6}{|l|}{ Explanatory variables } \\
\hline Age & 23.460 & 44 & 17.227 & 0 & 114 \\
\hline Surface & 127.974 & 100 & 82.566 & 25 & 600 \\
\hline Bedrooms & 2.336 & 2 & 1.081 & 0 & 6 \\
\hline WC & 0.526 & 1 & 0.569 & 0 & 3 \\
\hline Storage room & 0.472 & 0 & 0.500 & 0 & 1 \\
\hline Air conditioned & 0.361 & 0 & 0.481 & 0 & 1 \\
\hline View & 0.421 & 0 & 0.494 & 0 & 1 \\
\hline Fireplace & 0.462 & 0 & 0.499 & 0 & 1 \\
\hline Heat & 0.966 & 1 & 0.182 & 0 & 1 \\
\hline Elevator & 0.627 & 1 & 0.487 & 0 & 2 \\
\hline Furnished & 0.292 & 0 & 0.455 & 0 & 1 \\
\hline Garage & 0.472 & 0 & 0.500 & 0 & 1 \\
\hline
\end{tabular}

coefficients (multiplied by 100) of the continuous variables as the percentage impact of those variables on rental housing prices. For the dummy variables, the expression $[\exp (\beta)-1] * 100$ is used to interpret the percentage impact (Halvorsen \& Palmquist, 1980).

As indicated, in addition to modeling rental housing prices in Athens using the classical OLS method, we used RK to run a model with the GLS estimator. Table 2 shows the estimates of the model coefficients using OLS and RK. Severe multicollinearity was not detected in the model given that the highest variance inflation factor (VIF) is for the Age variable (7.4326) and does not exceed the value of 10 . However, the model disturbances exhibit spatial autocorrelation given that the Moran's I statistic $(\mathrm{I}=0.4242)$ is significant at the $5 \%$ level $(p=$ $0.000)$. To consider the spatial autocorrelation in the model disturbances, we used an exponential variogram model whose parameters are shown in Table 2 . The relative residual nugget effect (nugget/sill) is 0.33 , thus indicating clear spatial dependence, which was detected due to the significant value of the Moran's I statistic. The presence of spatial dependence in the model disturbances could be due to the existence of variables that are not included in the model, although they exhibit spatial autocorrelation due to the location variables, such as spatial contagion and location characteristics. The experimental variogram in Figure 3 shows that as the distance between dwellings increases, the variability between the residuals also increases. Three models (spherical, exponential, and Gaussian) were used to select the type of spatial autocorrelation structure, all of which yielded very similar results in terms of the R-squared of the RK model (Gaussian = 0.8419 , exponential $=0.8434$, and spherical $=0.8439)$. Ultimately, the exponential model was chosen as it is the most frequently used model in the literature (Webster \& Oliver, 2007). The figure also shows the adjusted variogram model, whose effective range is equal to 2,635.818 meters $\left(3^{*} 878.606\right)$. This distance indicates the area of influence of local variables on rental housing prices in Athens.

As can be seen in Table 2, the variables that are significant at the $5 \%$ and $10 \%$ levels have the expected signs in both models. As regards the goodness-of-fit of the model, it can be observed that the RK model is more suitable than the OLS one, since the R-squared has increased and the root-mean-square prediction error (RMSE) has decreased.

From the point of view of the housing market, it is clearly of interest to determine housing prices at any given location and thus obtain isovalue maps (Clapp, 2004; Yue, Liu, \& Fan, 2010). To do so, it is first necessary to estimate the price of housing at any point on the map. However, given that it is impossible to know the structural characteristics for all points on the map, we defined a standard dwelling. A standard dwelling was obtained by assigning the numerical value of the sample mean if the variable was continuous or the mode if the variable was binary.

Figure 4 shows the estimated values for a standard dwelling in Athens. As can be observed, the highest prices are found in the center of the city, around the Acropolis. 


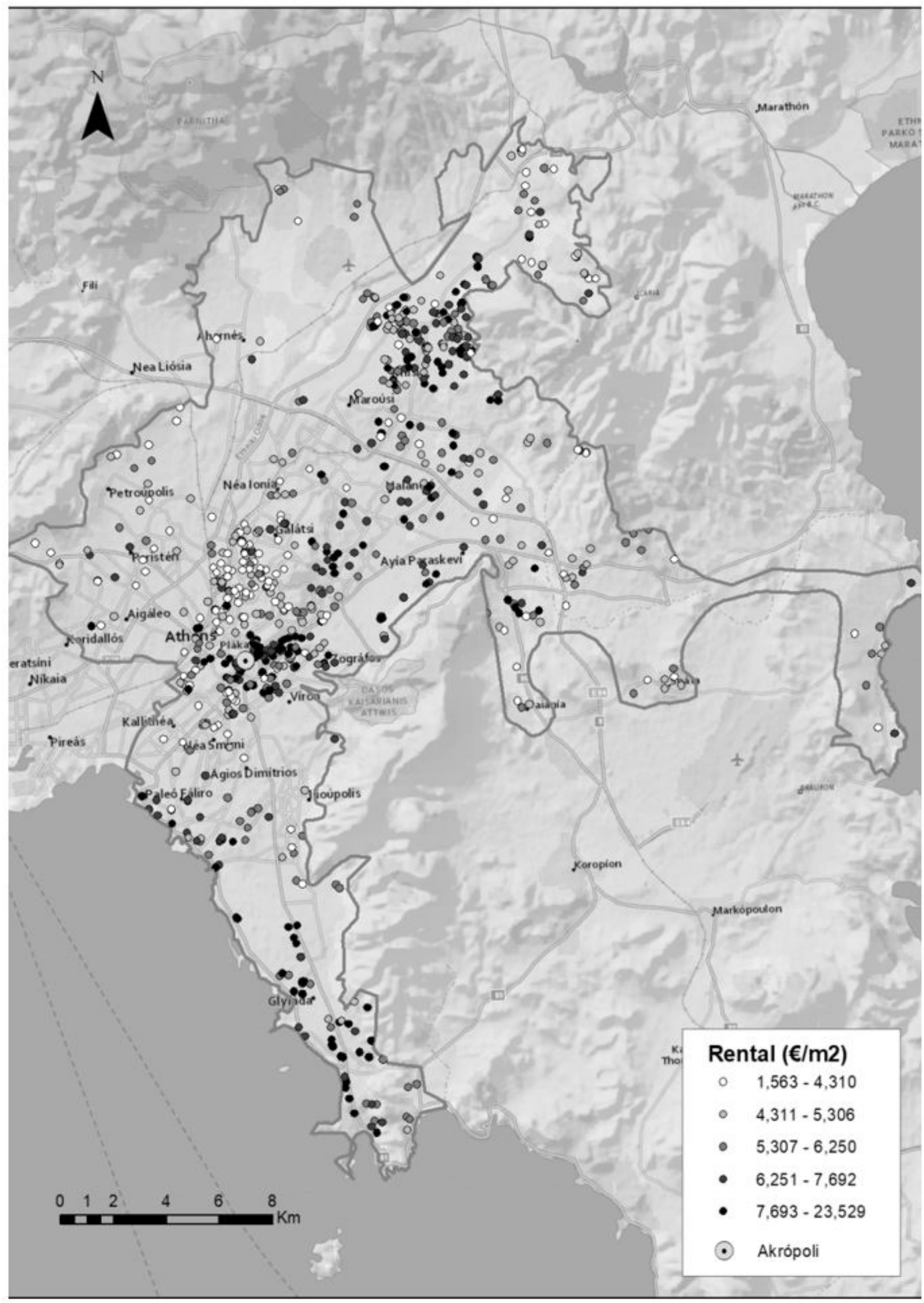

Figure 2. Location of the housing in the sample 
Table 2.

\section{Model estimated using OLS and RK. Dependent variable: Rental housing price}

\begin{tabular}{lcc}
\hline \multicolumn{1}{c}{ Explanatory variables } & OLS & RK \\
\hline Const. & $5.214(0.000)$ & $5.4425(0.000)$ \\
Age & $-0.0055(0.006)$ & $-0.0084(0.000)$ \\
Age-squared & $0.0001(0.000)$ & $0.0001(0.000)$ \\
Surface & $0.0038(0.000)$ & $0.0038(0.000)$ \\
Bedrooms & $0.0596(0.009)$ & $0.0719(0.000)$ \\
WC & $0.1348(0.000)$ & $0.0768(0.001)$ \\
Storage room & $0.0811(0.008)$ & $0.0314(0.020)$ \\
Air conditioned & $0.0789(0.005)$ & $0.0298(0.019)$ \\
View & $0.0963(0.000)$ & $0.0679(0.003)$ \\
Fireplace & $0.2052(0.000)$ & $0.1107(0.000)$ \\
Heat & $0.1758(0.015)$ & $0.0984(0.080)$ \\
Elevator & $0.0761(0.005)$ & $0.0734(0.002)$ \\
Furnished & $0.1493(0.000)$ & $0.1279(0.000)$ \\
Garage & $0.1867(0.000)$ & $0.1775(0.000)$ \\
Variogram & & Exponential \\
Nugget & & 0.0432 \\
Partial sill & - & 0.0848 \\
Range & & 878.606 \\
Model fit & & 0.8434 \\
R-squared & & 0.2768 \\
RMSE & 0.7504 &
\end{tabular}

Note: $\mathrm{N}=757 ; p$-values in parenthesis.

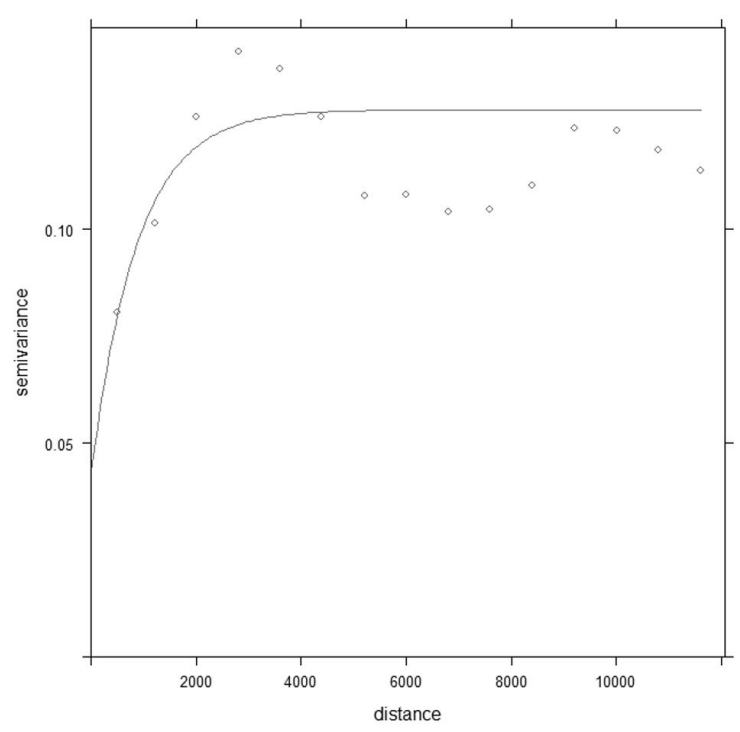

Figure 3. Experimental variogram and adjusted exponential model

There are several reasons for this. The main one is that the central business district and the most important monuments (Syntagma Square, the Cathedral, the Hellenic Parliament, most of the ministries, and almost all the embassies) are located in this area. This is also the central point where most of the shops, bars, restaurants, designer boutiques, museums, and other amenities and leisure facilities are located. In addition, there are a large number of hotels, banks, post offices, as well as subway, bus, and tram lines that provide easy access to the area.

However, the center is not the only area where high rental prices can be found. The prices in the southern coastal zone (Glyfada) are similar to in the central area. This is due to the proximity of the housing to the sea and the Port of Piraeus, which is the chief port in Greece and one of the most important in Europe. The presence of numerous hotels, the proximity to the city center, and the good transport links enable residents from these areas to enjoy the beaches while they can continue to work close to the main hub. In addition, there are numerous nautical companies, which are paramount to the country's economy.

Another high-priced area is located in the north (Kifissia), which is characterized by relatively new and exclusive housing owned by people with high purchasing power. This area is far enough from the center to escape the noise and hustle and bustle of the city and is surrounded by many green spaces and forests. The transport links to the center are good and there is quick access to the motorway out of Athens. Lastly, the area between Galatsi and Agia Paraskevi is also characterized by its high housing prices. 


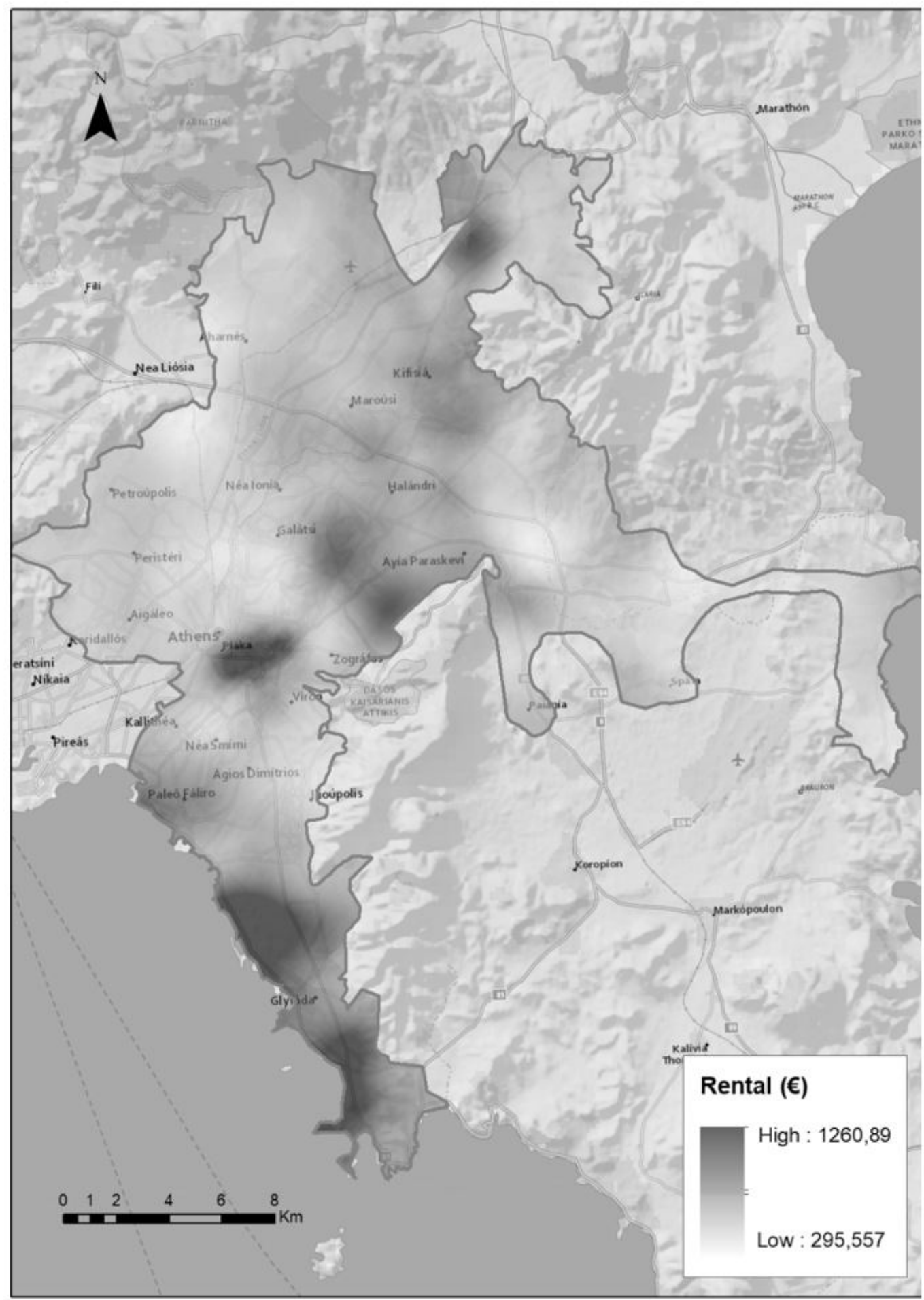

Figure 4. Rental price of standard dwellings

This is due to the numerous squares, parks, avenues, and green areas surrounding both districts. The extension of the subway into these areas has also increased rental prices. In contrast, one of the areas with the lowest prices in the city due to socio-economic problems is located between Aigaleo, Galatsi, and Peristeri. Lastly, the eastern zone also has low prices because it is far from the urban center and has poor transport links.

The results show the areas where the rents for residential properties are higher due to their cultural and environmental attractions, among other location characteristics. These same attractions are also highly 
valued in tourism accommodations. As a result, some of the available housing can be exploited for purely tourism purposes, which could lead to the touristification phenomenon, as is being observed in other geographical areas (Blanco-Romero et al., 2018; Yrigoy, 2019). This phenomenon consists of the displacement of an area's habitual residents by tourists as a result of the high demand for rental accommodation for tourism purposes.

Therefore, tools to determine the impact of location on rental housing prices could assist relevant authorities in their decision making. For example, the Athens City Council may be interested in determining the impact of location on rental prices in order to control the undesirable effects of tourist accommodation rental prices.

The methodology used in this study can also help in detecting the housing rent gap. The rent gap is calculated as the disparity between residential rentals and tourism rentals, which leads to more intensive use of housing (Ley, 1986; Smith, 1987). Moreover, models that help to determine and spatially represent rental prices can be useful for managing social policies that enable citizens to access an essential asset such as housing.

\section{Conclusions}

This study highlights the impact of location on rental housing prices by showing how the rent of a standard dwelling in the city of Athens varies depending on its location. To do so, we hypothesized that rental housing prices are not randomly spatially distributed, but rather that neighboring dwellings are affected by location factors in a similar way.

In addition, we assumed that neighboring homeowners will tend to offer similar rental prices due to the spatial contagion effect. Both location factors and spatial contagion lead to spatial autocorrelation in rental housing prices. To achieve the results obtained in this study, a geostatistical method was used (regression-kriging) that takes into account the structural characteristics of a dwelling, as well as the spatial autocorrelation caused by undetected location factors and spatial contagion.

The methodology enabled us to obtain an isovalue map of rental housing prices for standard dwellings, which can also be interpreted as a locational isovalue map given that the structural characteristics of standard dwellings are constant for the entire plane. The price of standard dwellings is higher in the most attractive areas (the Acropolis, Glyfada, Kifissia, Galatsi, etc.) since these are historic areas with higher environmental quality (proximity to the beach, green areas, etc.) and better transport links.

It should also be noted that these results may serve to anticipate the emergence of the touristification phenomenon given that these areas are attractive for both residential and tourism use.

We would like to highlight the usefulness of the methodology, which could help investors to determine where to target investments and assist public authorities in deciding where to focus urban management policies in order to control the undesirable effects of an excessive rise in rents caused by tourism.

Finally, one advantage of the methodology used in this work is that it can be applied to any city in the world, as data on rental housing prices, structural characteristics, and spatial location are easy to obtain through searches in real estate portals. The main differences between some cities and others would mainly be related to locational factors, which are difficult to reproduce in space, since they are specific to each city. However, another advantage of the proposed methodology is that it is not strictly necessary to specify these factors in the model.

\section{References}

Alonso, W. (1964). Location and Land Use: Toward a General The- ory of Land Rent: Cambridge: Harvard University Press.

Anselin, L. (1988). Spatial Econometrics: Methods and Models. Dordrecht: Kluwer Academic Publishers.

Bajat, B., Kilibarda, M., Pejović, M., \& Petrović, M. S. (2018). Spatial Hedonic Modeling of Housing Prices Using Auxiliary Maps. In J. C. Thill (ed). Spatial Analysis and Location Modeling in Urban and Regional Systems (pp. 97-122). Berlin, Heidelberg: Springer Berlin Heidelberg.

Basu, S., \& Thibodeau, T. G. (1998). Analysis of spatial autocorrelation in house prices. The Journal of Real Estate Finance and Economics, 17(1), 61-85.

Beimer, W., \& Maennig, W. (2017). Noise effects and real estate prices: A simultaneous analysis of different noise sources. Transportation Research Part D: Transport and Environment, 54, 282-286.

Blanco-Romero, A., Blázquez-Salom, M., \& Cànoves, G. (2018). Barcelona, Housing Rent Bubble in a Tourist 
City. Social Responses and Local Policies. Sustainability, 10(6), 2043. doi: https://doi.org/10.3390/su10062043

Bourassa, S. C., Cantoni, E., \& Hoesli, M. (2007). Spatial dependence, housing submarkets, and house price prediction. The Journal of Real Estate Finance and Economics, 35(2), 143-160.

Can, A. (1992). Specification and estimation of hedonic housing price models. . Regional Science and Urban Economics, 22(3), 453-474.

Cellmer, R. (2014). The possibilities and limitations of geostatistical methods in real estate market analyses. Real Estate Management and Valuation, 22(3), 54-62.

Clapp, J. M. (2004). A semiparametric method for estimating local house price indices. Real Estate Economics, 32(1), 127-160.

Cressie, N. (1991). Statistics for spatial data. USA: John Wiley \& Sons.

Cui, N., Gu, H., Shen, T., \& Feng, C. (2018). The Impact of Micro-Level Influencing Factors on Home Value: A Housing Price-Rent Comparison. Sustainability, 10(12), 4343.

Chau, K., \& Chin, T. (2003). A critical review of literature on the hedonic price model. International Journal for Housing Science and Its Applications, 27(2), 145-165.

Chen, J., Wu, Y., Guo, F., \& Wang, H. (2018). Domestic property and housing class in contemporary urban China. Journal of Housing and the Built Environment, 33(1), 91-109.

Chen, W. Y., \& Jim, C. (2010). Amenities and disamenities: A hedonic analysis of the heterogeneous urban landscape in Shenzhen (China). The Geographical Journal, 176(3), 227-240.

Chica-Olmo, J. (1995). Spatial estimation of housing prices and locational rents. Urban Studies, 32(8), 1331-1344.

Chica-Olmo, J., Cano-Guervos, R., \& Chica-Olmo, M. (2013). A Coregionalized Model to Predict Housing Prices. Urban Geography, 34(3), 395-412.

Chica-Olmo, J., Cano-Guervos, R., \& Chica-Rivas, M. (2019). Estimation of housing price variations using spatio-temporal data. Sustainability, 11(6), 1551. doi: https://doi.org/10.3390/su11061551

Chica-Olmo, J., Cano-Guervos, R., \& Tamaris-Turizo, I. (2018). Determination of buffer zone for negative externalities: Effect on housing prices. The Geographical Journal, 185(2), 222-236.

Christensen, R. (1987). Plane answers to complex questions: The Theory of Linear Models. New York: Springer-Verlag.

Danieli, Y., Stamatopoulou, E., \& Dias, C. (2018). The universal declaration of human rights: Fifty years and beyond. Londres: Routledge.

Diao, M., Leonard, D., \& Sing, T. F. (2017). Spatialdifference-in-differences models for impact of new mass rapid transit line on private housing values. Regional Science and Urban Economics, 67, 64-77.

Diao, M., Qin, Y., \& Sing, T. F. (2016). Negative externalities of rail noise and housing values: Evidence from the cessation of railway operations in Singapore. Real Estate Economics, 44(4), 878-917.

Dubin, R. A. (1988). Estimation of Regression Coefficients in the Presence of Spatially Autocorrelated Error Terms. The Review of Economics and Statistics, 70(3), 466-474.

Dubin, R. A. (1992). Spatial autocorrelation and neighborhood quality. Regional Science and Urban Economics, 22,(2), 433-452.

Dubin, R. A. (1998). Spatial autocorrelation: A primer. Journal of Housing Economics, 7(4), 304-327.

Dubin, R. A., Pace, J. K., \& Thibodeau, T. G. (1999). Spatial Autoregression Techniques for Real Estate Data. Journal of Real Estate Literature, 7, 79-95.

Efthymiou, D., \& Antoniou, C. (2013). How do transport infrastructure and policies affect house prices and rents? Evidence from Athens, Greece. Transportation Research Part A: Policy and Practice, 52, 1-22.

Eurostat (2018). Housing statistics. Eurostat. Retrieved from https://ec.europa.eu/eurostat/statistics-explained/ index.php/Housing_statistics/es. 
Fabusuyi, T. (2018). Is crime a real estate problem? A case study of the neighborhood of East Liberty, Pittsburgh, Pennsylvania. [Working Paper]. European Journal of Operational Research. Retrieved from https://papers.ssrn. com/sol3/papers.cfm?abstract_id=3061018

Fan, Q., Hansz, J. A., \& Yang, X. (2016). The Pricing Effects of Open Space Amenities. The Journal of Real Estate Finance and Economics, 52(3), 244-271.

Felus, Y. A. (2001). New methods for spatial statistics in geographic information systems (Dissertation). The Ohio State University. Ohio, USA. Retrieved from https://etd. ohiolink.edu/apexprod/rws_etd/send_file/send?accession =osu $1486400446373917 \&$ disposition=inline

Gallin, J. (2008). The long-run relationship between house prices and rents. Real Estate Economics, 36(4), 635-658.

Goodall, B. (2013). The economics of urban areas (Vol. 3). Oxford: Pergamon Press

Halvorsen, R., \& Palmquist, R. (1980). The interpretation of dummy variables in semilogarithmic equations. American Economic Review, 70(3), 474-475.

Harris, C. D., \& Ullman, E. L. (1945). The nature of cities. The Annals of the American Academy of Political and Social Science, 242(1), 7-17.

Hengl, T., Heuvelink, G., \& Rossiter, D. G. (2007). About regression-kriging: From equations to case studies. Computers \& Geosciences, 33(10), 1301-1315.

Hoch, I., \& Waddell, P. (1993). Apartment rents: Another challenge to the monocentric model. Geographical Analysis, 25(1), 20-34.

Iliopoulou, P., \& Stratakis, P. (2018). Spatial analysis of housing prices in the Athens Region, Greece. RELAND: International Journal of Real Estate \& Land Planning, 1, 304-313.

Korpi, W. (2018). The democratic class struggle (Vol. 22). Londres: Routledge.

Krause, A., \& Bitter, C. (2012). Spatial econometrics, land values and sustainability: Trends in real estate valuation research. Cities, 29(2), S19-S25.
Lancaster, K. J. (1966). A new approach to consumer theory. Journal of Political Economy, 74(2), 132-157.

Le Boennec, R., \& Salladarré, F. (2017). The impact of air pollution and noise on the real estate market. The case of the 2013 European Green Capital: Nantes, France. Ecological Economics, 138, 82-89.

Leamer, E. (2002). Bubble trouble? Your home has a P/E ratio too. UCLA Anderson Forecast, 1-11.

Lee, C.-I. (2007). Does provision of public rental housing crowd out private housing investment? A panel VAR approach. Journal of Housing Economics, 16(1), 1-20.

Ley, D. (1986). Alternative explanations for inner-city gentrification: a Canadian assessment. Annals of the Association of American Geographers, 76(4), 521-535.

Magginas, N., \& Pateli, E. (2009). Greek residential real estate market: Recovery in sight by mid-2010. National Bank of Greece, Economic and Market Analysis.

Matheron, G. (1970). La théorie des variables régionalisées et ses applications. Paris: Ecole Nationale Supérieure des Mines de Paris.

Moye, R., \& Thomas, M. (2018). Race and Housing Values: What Happens When Whites Don't All Move Out? City \& Community, 17(1), 109-133.

Nasreen, Z., \& Ruming, K. (2018). Room sharing in Sydney: A complex mix of affordability, overcrowding and profit maximisation. Urban Policy and Research, $37(2), 1-19$.

Nishi, H., Asami, Y., \& Shimizu, C. (2019). Housing features and rent: estimating the microstructures of rental housing. International Journal of Housing Markets and Analysis, 12(2), 210-225.

Osland, L. (2010). An Application of Spatial Econometrics in Relation to Hedonic House Price Modeling. Journal of Real Estate Research, 32(3), 289-320.

Ozanne, L., \& Thibodeau, T. (1983). Explaining metropolitan housing price differences. Journal of Urban Economics, 13(1), 51-66. 
Pagourtzi, E., Assimakopoulos, V., Hatzichristos, T., \& French, N. (2003). Real estate appraisal: A review of valuation methods. Journal of Property Investment \& Finance, 21(4), 383-401.

Papadimitriou, D. B., Nikiforos, M., \& Zezza, G. (2013). The Greek economic crisis and the experience of austerity: A strategic analysis. The Levy Economics Institute of Bard College, 1-25.

Ramos, P. (2015). Greece, a showcase of housing at democratized prices. Retrieved from https://www.elmundo.es/economi a/2015/07/10/559fa01c268e3efc178b457c.html

Rex, J. A. (1968). The sociology of a zone of transition. In R. E. Pahl (Ed.), Readings in urban sociology (pp. 211231). Amsterdā: Elsevier.

Rosen, S. (1974). Hedonic Prices and implicit markets: Product differentiation in pure com-petition. Journal of Political Economy, 82(1), 34-55.

Smith, N. (1987). Gentrification and the rent gap. Annals of the Association of American Geographers, 77(3), 462-465.

Swoboda, A., Nega, T., \& Timm, M. (2015). Hedonic analysis over time and space: the case of house prices and traffic noise. Journal of Regional Science, 55(4), 644-670.

Taipalus, K. (2006). A global house price bubble? Evaluation based on a new rent-price approach. Bank of Finland Research Discussion Paper (Working Paper No. 29). Recuperado de https://papers.ssrn.com/sol3/papers. cfm?abstract_id $=1018329$

Tobler, W. (1970). A computer model simulation of urban growth in the Detroit region. Economic Geography, 46(2), 234-240.
Trojanek, R., \& Gluszak, M. (2018). Spatial and time effect of subway on property prices. Journal of Housing and the Built Environment, 33(2), 359-384.

Tse, R. Y. C. (2002). Estimating Neighbourhood Effects in House Prices: Towards a New Hedonic Model Approach. Urban Studies, 39(7), 1165-1180.

Von Thünen, J. H. (1966). Isolated state: an English edition of Der isolierte Staat. Oxford: Pergamon Press.

Webster, R., \& Oliver, M. A. (2007). Geostatistics for environmental scientists. Chichester, England; New York: John Wiley \& Sons.

Wen, H., Jin, Y., \& Zhang, L. (2017). Spatial heterogeneity in implicit housing prices: Evidence from Hangzhou, China. International Journal of Strategic Property Management, 21(1), 15-28.

Wheaton, W. C. (1977). A bid rent approach to housing demand. Journal of Urban Economics, 4(2), 200-217.

Wulff, M. N., \& Maher, C. (1998). Long-term renters in the Australian housing market. Housing Studies, 13(1), 83-98.

Yrigoy, I. (2019). Rent gap reloaded: Airbnb and the shift from residential to touristic rental housing in the Palma Old Quarter in Mallorca, Spain. Urban Studies, 56(13), 2709-2726. doi: https://doi. org/10.1177/0042098018803261

Yue, W., Liu, Y., \& Fan, P. (2010). Polycentric urban development: The case of Hangzhou. Environment and planning. A: Economy and Space, 42(3), 563-577. 


\section{Financial support:}

Name of the funding agency/OR/ There are no funding agencies to report.

\section{Conflicts of interest:}

The authors have no conflict of interest to declare.

\section{Copyrights:}

RBGN owns the copyrights of this published content.

\section{Plagiarism analysis:}

RBGN performs plagiarism analysis on all its articles at the time of submission and after approval of the manuscript using the iThenticate tool.

\section{Authors:}

1. Jorge Chica-Olmo, PhD in Economic and Business Sciences, University of Granada. Spain. jchica@ugr.es

2. Rafael Cano-Guervos, PhD in Economic and Business Sciences, University of Granada. Spain. rcano@ugr.es

3. María-Despoina Moschovaki, Graduate in Statistics and post-graduate in Quantitative Methods for Economics and Business, University of Granada, Spain.

moschovakimaria@gmail.com

4. Ivan Tamaris-Turizo Graduate in Economics and post-graduate in Quantitative Methods for Economics and Business, University of Granada.

itamaris@unimagdalena.edu.co

\section{Authors' Contributions:}

$\mathbf{1}^{\text {st }}$ author: definition of research problem; development of hypotheses or research questions (empirical studies); development of theoretical propositions (theoretical work); definition of methodological procedures; literature review; statistical analysis; analysis and interpretation of data; critical revision of the manuscript; manuscript writing.

$2^{\text {nd }}$ author: definition of research problem; development of hypotheses or research questions (empirical studies);

development of theoretical propositions (theoretical work); definition of methodological procedures; literature review; statistical analysis; analysis and interpretation of data; critical revision of the manuscript; manuscript writing.

$3^{\text {rd }}$ author: development of hypotheses or research questions (empirical studies); development of theoretical propositions (theoretical work); definition of methodological procedures; data collection; literature review; statistical analysis; analysis and interpretation of data;

$4^{\text {th }}$ author: literature review; revision of the manuscript, analysis and interpretation of data. 